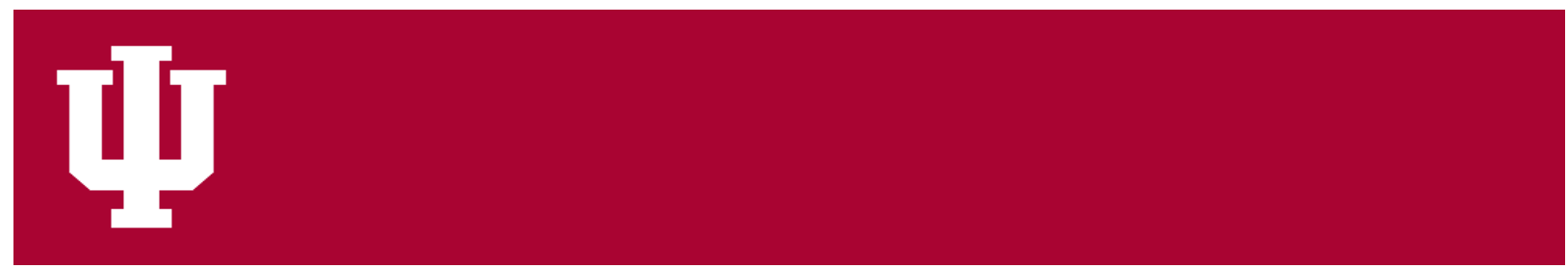

IUScholarWorks at Indiana University South Bend

\title{
Online Grocery Shopping: Consumer Motives, Concerns, and Business Models
}

Kempiak, Mike; Fox, Mark A

To cite this article: Kempiak, Mike, and Mark Fox. "Online Grocery Shopping:

Consumer Motives, Concerns, and Business Models." First Monday, vol. 7, no. 9, Sept. 2002, http://firstmonday.org/issues/issue7_9/fox/index.html.

This document has been made available through IUScholarWorks repository, a service of the Indiana University Libraries. Copyrights on documents in IUScholarWorks are held by their respective rights holder(s). Contact iusw@indiana.edu for more information. 


\title{
f i (B) $s+m \boldsymbol{x} \tilde{n} \mathbf{d} @ \boldsymbol{\eta}$
}

PEER-REVIEWED JOURNAL ON THE INTERNET

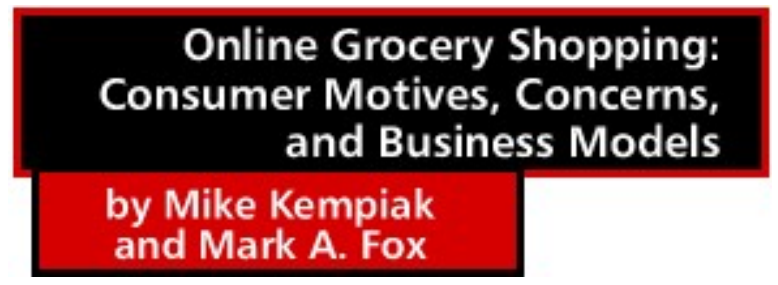

\begin{abstract}
Online Grocery Shopping: Consumer Motives, Concerns, and Business Models by Mike Kempiak and Mark A. Fox

Dot.com entrepreneurs failed spectacularly in their attempts to create e-grocery companies. This paper examines consumer motives and concerns with regard to online grocery shopping. The reasons for the success experienced by traditional bricks-and-mortar companies that have expanded into this market are also examined.
\end{abstract}

\section{Contents}

\author{
Introduction \\ Consumer Motives \\ Consumer Concerns \\ E-Grocery Business Models \\ Conclusions
}

\section{Introduction}

Groceries are different from many other products, such as music and books, that are commonly purchased online. Many grocery products are perishable and therefore timesensitive in terms of their delivery needs. In addition, groceries are a replacement product, i.e., the same basket of products is more-or-less purchased on a regular basis. Finally, groceries are high-touch items, meaning that consumers like to inspect the quality of items they are purchasing.

Five years ago online grocery sales were only $\$ 85$ million (Machlis, 1998); however, in 2002 Jupiter Media Metrix estimate that online grocery store revenue will reach $\$ 1.3$ billion (Lorek, 2001). This growing market had attracted an number of "pure-plays" - companies that focused exclusively on selling through the Internet, and attempted to replace traditional bricks-and-mortar supermarkets. Most of these pure-plays failed spectacularly. Today, 
traditional bricks-and-mortars stores are increasingly entering the online market in an attempt to leverage both brand awareness and create distribution efficiencies.

This paper reviews the online grocery market by identifying the characteristics of the consumer and the industry. Key success factors are identified and examples of e-grocery stores are provided to show how some companies succeeded in this market, while others failed.

\section{Consumer Motives}

The Food Marketing Institute (FMI) has identified reasons that people, generally speaking, choose to shop online (FMI, 2000). FMI research revealed that 86 percent of consumers go online or access their computer on a daily basis. Of these individuals, 70 percent use the Internet frequently for shopping. Those consumers between the ages of 25 to 34 are most likely to use the Internet for shopping. FMI also identified how respondents locate online shopping sites. The two main methods are looking in the Web site of a familiar store and doing a keyword search on a browser; Table 1 . These findings indicate that stores with a bricks-and-mortar presence have an advantage in attracting new users to their sites. Hence, as we shall see later, it is hardly surprising that pure-plays had difficulty establishing brand loyalty in this marketspace.

Table 1: How Respondents Locate Online Shopping Sites Source: Food Marketing Institute, 2000.

\begin{tabular}{|c|c|}
\hline How Respondents Locate Online Shopping Sites & Percentage \\
\hline Web site of a familiar store & 67 \\
\hline Keyword search in a Web browser & 67 \\
\hline Word of mouth & 54 \\
\hline Read about a Web site & 49 \\
\hline Advertisements on television & 47 \\
\hline Advertisements in magazines & 47 \\
\hline Radio & 18 \\
\hline Other & \\
\hline
\end{tabular}




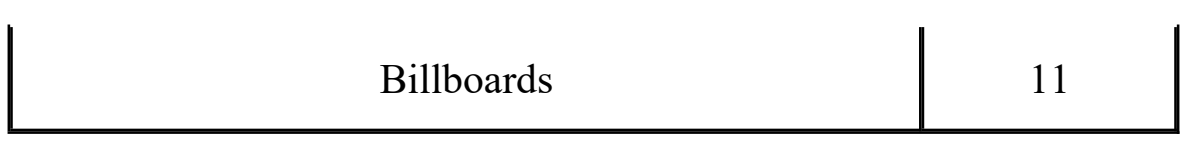

The decision to purchase groceries online occurs after consumers evaluate the benefits and costs of this decision versus using a traditional brick-and-mortar versus a straight online store. There are five critical elements that determine whether a consumer shops online or in a traditional grocery store (MyWebGrocer, 2001):

1. Price;

2. Ambiance;

3. Convenience;

4. Service; and,

5. Product variety.

Many of the bricks-and-mortar formats vying for consumers' attention are focused primarily on two of these elements, namely price and variety. However, owing to service fees incurred when shopping online, traditional grocery stores typically experienced a comparative price advantage over e-grocers (MyWebGrocer, 2001). E-grocers were found to be comparable to their bricks-and-mortar counterparts in terms of product variety, and were viewed more favorably on the dimensions of ambience, convenience and service. With regard to service and convenience, the following observations were made:

"While service is often mentioned as an attribute offered by retailers, consumer perceptions of the service levels offered is quite different and not highly valued. Convenience offerings are limited to distance and ingress/egress availability" [1].

The service aspect of e-grocers appears to be a major attraction for consumers. Today's jobs have increased work hours. Also, changing family structures have resulted in more single parent families with less time on their hands (see, for example, Lobel, Googins and Bankert, 1999; U.S. Department of Labor, 2000). Consumers are also busier than ever, more mobile, more affluent, and increasingly impatient with mundane time-consuming tasks. As a consequence of these social and attitudinal changes, people are drawn to convenient, dependable alternative solutions for mundane, repetitive but necessary tasks; hence, the growing appeal of e-grocery shopping. In this regard, Morganosky and Cude (2000) found that 73 percent of e-grocery shoppers reported that convenience and saving time as the primary reasons that they use the Internet to buy groceries.

The appeal of e-grocery services is also influenced by many consumers findings grocery shopping a stressful activity. In a study of 239 respondents, Aylott and Mitchell (1998) found two major stressors associated with traditional grocery shopping, namely crowding and queuing (the later was generally influenced by the former). With regard to these concerns the authors note that:

"Crowding is disliked because it frustrates customers achieving their task as easily as they would like ... It may also invoke feelings of claustrophobia in some people ... Queuing is a function of crowding and adds to the feeling of frustration and the distress this causes" [2] 
Other research supports the notion that time constraints and perceptions of grocery shopping as stressful contribute to the decision to the decision to e-grocery shop. For example, the typical U.S. e-grocery store shopper is a dual-income suburban family (Cude and Morganosky, 2000). According to Keh and Shieh (2001) these such consumers are typically time-starved, have above average income and dislike grocery shopping. Of related interest, Morganosky and Cude (2000) reported that over 50 percent of e-grocery shoppers earned over US\$50,000 per year, and 80 pecent of e-grocery households comprised two or more adults.

In addition to time-starved and stressed consumers, individuals with disabilities related to age and health are another prominent market for e-grocery services (Heikkila et al., 1999). These consumers often have lower incomes, live alone and phone in orders, rather than order online (Cude and Morganosky, 2000). Heikkila et al. [3] observe that, "[t]he current, inarguably efficient retail system does not take the needs of the elderly and disabled into account." In particular, some disabled or elderly consumers may have difficulty in shopping in a traditional brick-and-mortar environment. In conducting research on this topic in Finland, Heikkila et al. (1999) discovered that the disabled and elderly were the second most often mentioned target market. The prominence of this market is also supported by Morganosky and Cude (2000), who find that 14.8 percent of e-grocery shoppers cite physical constraints as the primary reason that they use the Internet to buy groceries.

In contrast to the motives for the above mentioned target markets, another target market baby boomers reaching their senior years - tend to e-grocery shop for convenience and novelty (Cude and Morganosky, 2000).

A study by MyWebGrocer reveals some interesting data pertaining to consumers who use online grocery stores. Most of these users are near major metropolitan areas and - not surprisingly - live in suburbs where the services tend to be offered. Also, consumers who shop online generally place orders over US $\$ 100$. Online grocery customers are also likely to replace repeat orders. Barsh, Crawford, and Grosso (2000) observe that:

"Moreover, within a local market, it can be relatively easy to reach sufficient scale - sales of perhaps less than three percent of the total, the equivalent of about 13 supermarkets. With relatively low scale requirements and high customer values, as we as minimal margin advantages for established retailers, pure plays ... have a great opportunity to succeed despite the huge investment needed for distribution infrastructure" [4]

\section{Consumer Concerns}

Although the research discussed so far indicates a strong conceptual interest in shopping online, the findings also point to some consumer concerns. In particular, the research by MyWebGrocer indicates that consumers were concerned about on-time delivery, the quality of produce, and the limited selection and variety of goods on the site. It was revealed that after registering, shoppers did not order in the same session since they did not have the time or did not find their favorite brands. Consumers simply stopped shopping online because of 
repeated bad experiences, including not being able to find their favorite products.

Online security and privacy are also of concern to consumers (see Cude and Morganosky, 2000). In particular, security issues generally revolve around the transfer of personal and financial information (for example, addresses, telephone numbers, credit card numbers, etc.) over the Internet. Another privacy concern relates to the use of online consumer demographic and taste-related data. Online stores gather this information and can use it to target costumers or sell to marketing firms for marketing analysis. However, this generally occurs without asking the consumer if they would like to option out of this data collection.

A survey by the Food Marketing Institute gathered specific information related to online grocery purchases (FMI, 2000). Consumer who did not shop online cited two major reasons for this: (1) wanting to see and touch the foods they purchase; and, (2) inconvenient delivery times and methods. For those consumers who did purchase groceries online, the most popular items purchased are shown in Table 2. Food is the most popular category, followed by health and beauty care items. The most popular food products are dry goods, representing 65 percent of food products purchased. One-third of respondents purchased frozen food or meat. Three out of every ten consumers purchased dairy items. Less than 25 percent have purchased produce items.

Table 2: Groceries Purchased Online

Source: Food Marketing Institute, 2000.

\begin{tabular}{|c|c|}
\hline Most Popular Grocery Category Purchased Online & Percentage \\
\hline Food & 88 \\
\hline Health and beauty care & 53 \\
\hline Vitamins, herbal remedies and beauty aids & 43 \\
\hline Household cleaners & 38 \\
\hline Pet supplies & 35 \\
\hline
\end{tabular}

Some areas of consumer dissatisfaction are apparent from the FMI survey. In particular, of those consumers who purchased produce online only 45 percent said that they would never purchase produce again. Similarly, only 42 percent of those who purchased meat said they would never purchase meat again online. Of related interest, Morganosky and Cude (1998) discovered that 55 percent of e-grocery consumers would not purchase meats and/or produce online. Taken together, these findings indicate consumer concerns regarding the quality of produce delivered and/or issues of control that consumers can exhibit when choosing specific items for purchase. 
Despite these concerns, purchasers generally rate the experience of buying groceries online highly favorably (FMI, 2000). Eighty percent say orders are correct, fresh, undamaged and shipped in a timely manner.

\section{E-Grocery Business Models}

As the preceding data indicate, there are some shortcomings apparent with regard to egrocery business models (Keh and Shieh, 2001). One major shortcoming of these models is that they limit on sensory perceptions of the product, i.e., consumers cannot see, touch and smell the products shown on the monitor. Also, for consumers to be convinced that delivery of products to their front door is convenient, the delivery time must be relatively short. Technology must also improve so that graphic displays do not require a long time to download. Additionally, online security is always a concern and is the main reason why consumers are reluctant to buy online. Finally, the issue of consumer privacy and how online stores will handle the large database of consumer preferences must be addressed.

Concerns still abound with regard to the pure-play e-grocery business model (Partch, 2001). The distribution centers required for this concept require a large amount of capital. In the wake of failing dot-coms, the availability of financial backers for such ventures has declined. Even with distribution centers in place, pure plays often must often be operating at full capacity to make them pay for themselves. With a startup operation and limited brand identification, it is difficult to achieve this efficiency, particularly in the short term. These concerns are warranted in light of the failure of many pureplay e-grocers, notably Webvan, Streamline, Homegrocer and Shoplink (Tanskanen, Yrjola and Holmstrom, 2002).

Peapod USA is one of the few surviving companies that started off as a pure play. However, this survival is largely attributable to its acquisition by the traditional grocery retailer Royal Ahold. This gave Peapod access to Ahold's cost- effective supply chain. It also formed a hybrid order fulfillment comprised of stores and distribution centers. This was more efficient and scalable.

Traditional grocery retailers that have ventured online have been more successful than pure plays. For example, Teco decided to grow one step at a time. They spent five years finetuning and developing their online order and delivery system. Currently, Tesco provides egrocery service through one-third of their 690 British outlets. This allows Tesco to be within a half-hour of 91 percent of the British population.

The comparative success of bricks-and-mortar stores that expand into an Internet environment is attributable to a the following factors:

- Existing stores have brand recognition and an established reputation;

- There are economies of scale, especially for the larger chains; and,

- Traditional stores are further along on the experience curve in this industry.

On a smaller scale, MyWebGrocer provides Internet services for 160 supermarkets in twenty states. This is a turnkey method to establish online stores. MyWebGrocer maintains 
the database used by the store and includes private label items as well as perishables. MyWebGrocer also maintains weekly prices and item additions or deletions. By offering this valuable service to the smaller grocery stores, MyWebGrocer believes they have a valuable business model. To make this business model successful, Mike Spindler, President of MyWebGrocer, makes the following suggestions:

- Leverage your reputation and current marketing by including existing store name in the Web address;

- Prominently feature the online site in all advertising and in-store activities;

- Show pictures of all products being sold;

- Have a sign-in sheet right in the store so customers can leave their e-mail address;

- Contact the local media when launching a site;

- Contact the media again with "human interest" story ideas, providing the list of customers who are happy with the service;

- Develop partnerships with local corporations to offer online shopping from the office;

- Team with local Internet Service Providers (ISPs); and,

- Contact local daycare centers to target busy parents []․

Irrespective of the scale of operations, e-grocers will only survive if the provide real value to consumers. With the small profit margins, competition on the basis of price should not be used to obtain a competitive advantage since this would hurt the industry as a whole. Some examples sources of value for consumers include:

- Emulating superior service through a user-friendly Web site;

- Being responsive to customers delivery time requirements;

- Enhancing the quality of products delivered with refrigerated delivery systems; and,

- Using innovative ideas to meet the needs of different customer groups, for example, special services for the aged and disabled.

\section{Conclusions}

Online grocery services meet a number of consumer needs including providing products for niche markets or helping the time starved consumer shop for the mundane weekly groceries. By delivering products to consumers' homes, the homebound aged and handicapped can participate in the shopping experience. Even though there has been a great decline in the number of pure-play online stores, there appears to be a solid market for shopping online. The major business model that is working today requires the support of the established bricks-and-mortar supermarkets. This model is effective as it creates distribution efficiencies and leverages reputation, which is an important consideration for consumers in light of the perishable nature of many grocery products. Em

\section{About the Authors}

Mike Kempiak is a MBA student in the School of Business \& Economics at Indiana 
University South Bend.

E-mail: mkempiak@aol.com

Mark A. Fox is Associate Professor of Management \& Entrepreneurship in the School of Business \& Economics at Indiana University South Bend.

Web: http://www.iusb.edu/ mfox1

E-mail: mfox1@iusb.edu

\section{Notes}

1. MyWebGrocer, 2001, p. 2.

2. Aylott and Mitchell, 1998, p. 365.

3. Heikkila et al., 1999, p. 390.

4. Barsh, Crawford, and Grosso, 2000, p. 106.

5. Mike Spindler, President of MyWebGrocer.

\section{References}

R. Aylott and V-W. Mitchell, 1998. "An exploratory study of grocery shopping stressors," International Journal of Retail \& Distribution Management, volume 26, number 9, pp. 362373. http://dx.doi.org/10.1108/09590559810237908

J. Barsh, B. Crawford and B. Grosso, 2000. "How E-tailing Can Rise from the Ashes," McKinsey Quarterly, issue 3, pp. 98-109.

B. Cude and M. Morganosky, 2000. "Online Grocery Shopping: An Analysis of Current Opportunities and Future Potential," Consumer Interests Annual, volume 46, pp. 95-100.

Food Marketing Institute, 2000. "The e-Tail Experience: What Grocery Shoppers Think about Online Shopping 2000 - Executive Summary," at http://www.fmi.org/e business. etailexperience.htm, accessed 30 June 2002.

J. Heikkila, J. Kallio, T. Saarinen and K. Virpi, 1998. "Grocery Shopping for the Elderly and Disabled: Finnish EC Experiments," Electronic Markets, volume 8, number 2, pp. 389402. http://dx.doi.org/10.1080/10196789800000019

H.T. Keh and E. Shieh, 2001. "Online Grocery Retailing: Success Factors and Potential Pitfalls," Business Horizons, volume 44, number 4, pp. 73-83.

http://dx.doi.org/10.1016/S0007-6813(01)80050-1

S.A. Lobel, B.K. Googins, and E. Bankert, 1999, "The Future of Work and Family: Critical 
Trends for Policy, Practice, and Research," Human Resource Management, volume 38, issue 3, pp. 243-254. http://dx.doi.org/10.1002/(SICI)1099-050X(199923)38:3<243::AIDHRM6>3.0.CO;2-T

L. Lorek, 2001. "Online Grocery Business Still Ripe," Interactive Week (16 July), p. 34.

M. Morganosky and B. Cude, 2000. "Consumer response to online grocery shopping," International Journal of Retail \& Distribution Management, volume 28, number 1, pp. 1726. http://dx.doi.org/10.1108/09590550010306737

MyWebGrocer.com, 2001. "Online Grocery Shopping: Learnings from the Practitioners," at http://www.fmi.org/e business/webgrocer.hmtl, accessed 30 May 2002.

Ken Partch, 2001. "The Trouble with Online Grocery," Supermarket Business Magazine, volume 56, issue 8 (15 August), p. 74.

K. Tanskanen, H. Yrjola and J. Holmstrom, 2002. "The Way to Profitable Internet Grocery Retailing - Six Lessons Learned," International Journal of Retail \& Distribution Management, volume 30, number 4, pp. 169-178. http://dx.doi.org/10.1108/09590550210423645

U.S. Department of Labor, 2000. "Futurework: Trends and Challenges for Work in the 21st Century," Occupational Outlook Quarterly (Summer), pp. 31-36.

\section{Editorial history}

Paper received 20 July 2002; accepted 14 August 2002.

\section{Contents Index}

Copyright $\subseteq 2002$, First Monday

Copyright $\underline{\text { C } 2002, ~ M i k e ~ K e m p i a k ~}$

Copyright $\subseteq 2002$, Mark A. Fox

Online Grocery Shopping: Consumer Motives, Concerns, and Business Models by Mike Kempiak and Mark A. Fox

First Monday, volume 7, number 9 (September 2002),

URL: http://firstmonday.org/issues/issue7_9/fox/index.html 